\title{
Multi-response Optimization of Ultrasound-assisted Extraction of Bioactive Components from Medicago sativa L.
}

\author{
Barbara Fumić, ${ }^{1,2}$ Mario Jug, ${ }^{3}$ Marijana Zovko Končićc ${ }^{1, *}$
}

\author{
1 Department of Pharmacognosy, Faculty of Pharmacy and Biochemistry, University of Zagreb, A. Kovačića 1, 10000 Zagreb \\ 2 Xellia, Slavonska avenija 24, 10000 Zagreb, Croatia \\ ${ }^{3}$ Department of Pharmaceutical Technology, Faculty of Pharmacy and Biochemistry, University of Zagreb, A. Kovačića 1, 10000 Zagreb \\ * Corresponding author's e-mail address: mzovko@pharma.hr
}

RECEIVED: October 10, 2017 * REVISED: November 02, 2017 * ACCEPTED: November 06, 2017

\begin{abstract}
Response surface methodology was used to optimize experimental conditions for ultrasound-assisted extraction of functional components from Medicago sativa L. (Fabaceae) aerial parts. The procedure was performed according to the Box-Behnken design. The independent variables were ethanol concentration $\left(X_{1}\right)$, temperature $\left(X_{2}\right)$, and $\mathrm{pH}\left(\mathrm{X}_{3}\right)$, while the responses were extraction yield, DPPH radical scavenging activity of the extracts (RSA IC 50 ), content of total phenols (TP), total flavonoids (TF) and total phenolic acids (TPA). The response values of the extracts prepared at optimum conditions $\left(X_{1}, X_{2}, X_{3}\right)$ were: yield $\left(162 \mathrm{mg} / \mathrm{ml}, 20 \%, 60{ }^{\circ} \mathrm{C}, 5.5\right), \operatorname{TP}\left(6.63 \mathrm{mg} / \mathrm{ml}, 100 \%, 60{ }^{\circ} \mathrm{C}, 5.5\right)$, TF $\left(0.292 \mathrm{mg} / \mathrm{ml}, 100 \%, 23{ }^{\circ} \mathrm{C}, 5.5\right)$, TPA $\left(0.275 \mathrm{mg} / \mathrm{ml}, 100 \%, 23{ }^{\circ} \mathrm{C}, 8.5\right)$ and RSA IC $50\left(3.97 \mathrm{mg} / \mathrm{ml}, 40 \%, 60{ }^{\circ} \mathrm{C}, 7.0\right)$. The predicted values matched well with the observed ones indicating the suitability of the selected models for extraction of bioactive compounds from $M$. sativa.
\end{abstract}

Keywords: Medicago sativa, Fabaceae, polyphenols, radical scavenging activity, response surface methodology.

\section{INTRODUCTION}

$\mathbf{M}$ EDICAGO sativa L., Fabaceae (alfalfa or lucerne), is a perennial herbaceous plant species with a long history of medicinal and nutritional use in Europe, Asia and America. As a traditional herbal medicine, it is used for numerous indications, such as treatment of arthritis, menstrual irregularities, kidney and bladder disorders, central nervous system disorders, cough, sore muscles, as well as a rejuvenator, antidiabetic, antioxidant, antiinflammatory, antifungal, anti-asthmatic, antimicrobial, diuretic and galactagogue agent. In addition, its sprouts and extracts are used as food and food supplements, respectively. In the United States, alfalfa is included in the Food \& Drug Administration GRAS (generally regarded as safe) category, while the Council of Europe lists alfalfa as a source of natural food flavoring. It is one of the oldest plants used as fodder and one of the most cultivated legumes, with production reaching 436 million tons in the US alone..$^{[1-3]}$
M. sativa contains a variety of phytochemicals, including phenolic and other antioxidants. ${ }^{[2,4]}$ The value of natural antioxidants in food and medicinal plants is now widely recognized, particularly due to their role in the prevention of degenerative disorders such as cancer and cardiovascular diseases.[5] Alfalfa contains also some specific classes of phenolic compounds that have distinct pharmacological features. Among them, the most interesting are phenolic compounds.[6] They have demonstrated estrogenic ${ }^{[7]}$ and apoptotic activity, ${ }^{[8]}$ and certainly contribute to many of the numerous observed pharmacological properties of $M$. sativa. ${ }^{[1,2,4]}$

Ultrasonic-assisted extraction (UAE) is an inexpensive, rapid, simple and efficient technique for extraction, most often used for solid/liquid systems. In $\mathrm{UAE}$, transmission of mechanical waves through a fluid causes oscillation of the molecules around their equilibrium position. In plant material, this may lead to a disruption of the cellular walls, particle size reduction and enhanced mass transfer across cell membranes. All this increases the 
solvent access to the target compounds resulting in improved extraction efficiency. ${ }^{[9]}$ UAE is characterized by relatively high reproducibility, short time of extraction, low solvent consumption, as well as low extraction temperature and energy input. Those characteristics render it appropriate for extraction of wide array of bioactive natural compounds, including chemically sensitive ones, such as polyphenols. ${ }^{[10]}$

UAE extraction conditions can greatly affect the yield and the composition of the prepared extracts, especially if target compounds are sensitive to oxidation and other types of degradation. Among numerous factors that can influence the efficiency of UAE, solvent type selection has been recognized as the most important. The effectiveness of UAE depends on the solvent's capacity of adsorbing and transmitting the ultrasound energy. Polarity of the solvent, its viscosity, vapor pressure and surface tension are the key factors that impact the cavitation efficiency. Due to its wide availability and lack of toxicity, water is by far the most appropriate solvent for the extraction of medicinal plants bioactive principles. Water is closely followed by ethanol, which is affordable and natural solvent obtainable from renewable sources. ${ }^{[10]}$ Another important extraction variable is the temperature. High temperature may improve the extraction process by reducing the viscosity of the solvent and increasing kinetic energy of the molecules in the solutions. However, high temperature may also cause degradation of the extracted phenolic and other sensitive compounds. In addition to temperature, $\mathrm{pH}$ of the solvent can also affect the extraction efficiency. For example, $\mathrm{pH}$ changes may cause ionization of weak acids and bases, thus increasing their solubility in water. However, extreme $\mathrm{pH}$ values can also lead to degradation of the target compounds[11] The variations of the aforementioned parameters are inevitably reflected not only on the composition, but also on the biological activity of plant extracts. Therefore, the extraction conditions must be carefully selected to ensure the extract of desired characteristics of the prepared extracts. ${ }^{[12]}$

An efficient extraction process should maximize the recovery of target compounds with minimal degradation, resulting in an extract with high biological activity. Ideally, this should be accomplished using environmentally friendly technologies and low-cost raw materials and solvents. ${ }^{[12]}$ To achieve this, a fine-tuning of the experimental conditions is often needed, which requires a large number of experiments to be performed. Response surface methodology (RSM) is a collection of mathematical and statistical techniques for modeling and optimization of complex processes. It enables creating an empirical model by development of an adequate functional relationship between a response(s) of interest and a number of associated input variables. The use of RSM effectively reduces number of experimental trials needed to evaluate multiple parameters and their interactions. Therefore, it is widely used in optimizing the extraction of polyphenols, ${ }^{[13,14]}$ alkaloids, ${ }^{[15]}$ and other biologically active compounds from herbal material. Examples also include use of RSM for optimization of UAE of phenolic antioxidants such as anthocyanines, ${ }^{[10]}$ phenolic acids, and flavonoids. ${ }^{[14]}$

As mentioned previously, M. sativa and its extracts contain several classes of polyphenolic phytochemicals which, through antioxidant and other biological activities, can exert beneficial effects on human organism. Previous research has shown that ethanol is an excellent solvent for the extraction of $M$. sativa constituents. ${ }^{[16,17]}$ However, detailed extraction analysis has not been performed, especially regarding $\mathrm{pH}$ conditions. Since seemingly similar extraction procedures can significantly affect the yield and the composition of plant extracts, the aim of this work was to perform a comprehensive investigation of the extraction variables influences (ethanol concentration, temperature and $\mathrm{pH}$ of extraction solvent) on content of phenolic antioxidants (yield, total phenols, flavonoids and phenolic acids), as well as antiradical activity of $M$. sativa extracts by RSM.

\section{EXPERIMENTAL}

\section{Plant Materials and Chemicals}

Aerial parts of $M$. sativa were collected in the surroundings of Zagreb (lake Jarun, $45^{\circ} 46^{\prime} 43.3^{\prime \prime} \mathrm{N} 15^{\circ} 54^{\prime} 46.8^{\prime \prime} \mathrm{E}$ ), dried and stored in a well-ventilated room, protected from light. Plant material was identified by Vedran Šegota, expert associate at the Department of Botany, Faculty of science, University of Zagreb. Voucher specimens are deposited in the Department of Pharmacognosy, Faculty of Pharmacy and Biochemistry, University of Zagreb, Zagreb, Croatia. Folin-Ciocalteu phenol reagent, 2,2-diphenyl-1-picrylhydrazyl (DPPH), gallic acid monohydrate ( $\geq 99 \%)$, apigenin ( $\geq 99 \%$ ), kaempferol ( $\geq 99 \%$ ), p-coumaric acid $(\geq 98.0 \%$ ) and ferulic acid ( $\geq 99 \%$ ) were purchased from Sigma-Aldrich (US). Methanol was HPLC grade. Other reagents and chemicals were of analytical grade.

\section{Preparation of Extracts}

Prior to the extraction, the dried aerial parts of $M$. sativa were milled and passed through a sieve of $850 \mu \mathrm{m}$ mesh size. Powdered plant material ( $2 \mathrm{~g}$ ) was suspended with 25 $\mathrm{ml}$ of the appropriate solvent in a $50 \mathrm{ml}$ Erlenmeyer flask. $\mathrm{pH}$ of the solvent was previously adjusted using the appropriate amount of either $1 \mathrm{M} \mathrm{NaOH}$ or $1 \mathrm{M} \mathrm{HCl}$. The extraction was performed in an ultrasonic bath (Bandelin SONOREX Digital 10 P DK 156 BP, Germany) at ultrasonication power of $720 \mathrm{~W}$ and frequency of $35 \mathrm{~Hz}$. The bath was temperature-controlled according to the 
Table 1. The Box Benken design and results of experiments

\begin{tabular}{|c|c|c|c|c|c|c|c|c|}
\hline Run & $\begin{array}{c}x_{1} / \\
\%, v / v\end{array}$ & $\begin{array}{l}\mathrm{X}_{2} / \\
{ }^{\circ} \mathrm{C}\end{array}$ & $X_{3}$ & $\begin{array}{l}\text { Yield } \\
\mathrm{mg} / \mathrm{ml}\end{array}$ & $\begin{array}{c}\mathrm{TP} \\
\mathrm{mg} / \mathrm{ml}\end{array}$ & $\begin{array}{c}\mathrm{TF} \\
\mathrm{mg} / \mathrm{ml}\end{array}$ & $\begin{array}{c}\text { TPA } \\
\mathrm{mg} / \mathrm{ml}\end{array}$ & $\begin{array}{c}\mathrm{RSA}_{\mathrm{IC}} \mathrm{C}_{50} \\
\mathrm{HME} \mathrm{mg} / \mathrm{ml}\end{array}$ \\
\hline 1 & 100 & 60 & 7 & 148 & 6.30 & 0.270 & 0.188 & 6.92 \\
\hline 2 & 50 & 60 & 8.5 & 152 & 6.50 & 0.278 & 0.120 & 4.71 \\
\hline 3 & 0 & 60 & 7 & 112 & 5.27 & 0.199 & 0.177 & 5.26 \\
\hline 4 & 0 & 40 & 5.5 & 46 & 4.73 & 0.175 & 0.271 & 9.54 \\
\hline 5 & 0 & 20 & 7 & 110 & 5.36 & 0.202 & 0.197 & 9.40 \\
\hline 6 & 0 & 40 & 8.5 & 124 & 5.65 & 0.215 & 0.214 & 9.13 \\
\hline 7 & 100 & 40 & 5.5 & 158 & 6.62 & 0.283 & 0.184 & 5.09 \\
\hline 8 & 50 & 40 & 7 & 150 & 5.64 & 0.241 & 0.241 & 3.27 \\
\hline 9 & 100 & 20 & 7 & 60 & 5.87 & 0.251 & 0.253 & 7.14 \\
\hline 10 & 50 & 20 & 8.5 & 32 & 5.26 & 0.198 & 0.230 & 11.15 \\
\hline 11 & 50 & 40 & 7 & 128 & 5.40 & 0.231 & 0.241 & 6.93 \\
\hline 12 & 50 & 40 & 7 & 130 & 5.19 & 0.222 & 0.229 & 4.78 \\
\hline 13 & 100 & 40 & 8.5 & 42 & 5.16 & 0.194 & 0.227 & 10.29 \\
\hline 14 & 50 & 40 & 7 & 132 & 5.45 & 0.206 & 0.202 & 6.70 \\
\hline 15 & 50 & 60 & 5.5 & 114 & 5.41 & 0.205 & 0.180 & 4.70 \\
\hline 16 & 50 & 20 & 5.5 & 150 & 5.40 & 0.231 & 0.169 & 6.74 \\
\hline 17 & 50 & 40 & 7 & 128 & 5.77 & 0.220 & 0.218 & 7.03 \\
\hline
\end{tabular}

$\mathrm{X}_{1}$ - Ethanol concentration; $\mathrm{X}_{2}-$ Temperature $\mathrm{X}_{3}-\mathrm{pH}$ of extraction solvent;

TP - Total phenols; TF - Total flavonoids; TPA - Total phenolic acids; RSA - Radical scavenging activity; HME - Herbal material equivalents.

extraction conditions presented in Table 1 . Upon the extraction, the mixture was filtered using folded filter papers S\&S 589/1 $1 / 2$ (Germany) and diluted with the water to a volume of $25.0 \mathrm{ml}$. All the extracts were stored at $+4{ }^{\circ} \mathrm{C}$ in the dark until use. Yield was determined as the weight of dry matter in $1 \mathrm{ml}$ of the extract using the Equation 1, as follows

$$
\text { Yield }=a / b
$$

Where $a$ is the weight of the dry extract $(\mathrm{mg})$ and $\mathrm{b}$ is the volume of the extract before evaporation.

\section{HPLC Analysis of Phenolic Acids and Flavonoids}

For determination of phenolic composition, standards were prepared in concentration of $0.2 \mathrm{mg} / \mathrm{mL}$ in methanol while the extracts were prepared in concentration $2 \mathrm{mg} / \mathrm{mL}$. For hydrolysis, in $1 \mathrm{~mL}$ of the corresponding extract solution $400 \mu \mathrm{l} 6 \mathrm{M} \mathrm{HCl}$ was added. The obtained mixtures were heated for 2 hours in water bath and then filtered to $5 \mathrm{~mL}$ volumetric flask. The precipitate on filter paper was washed with methanol and added to the flask contents to the volume. Phenolic acids and flavonoids were quantified using an HPLC instrument (Agilent 1200 series, Agilent Technologies, USA) equipped with an autosampler and DAD detector. Zorbax Eclipse XDB-C18 column (5 $\mu \mathrm{m}, 12.5 \mathrm{~mm}$ $\times 4.6 \mathrm{~mm}$, Agilent, USA) and Zorbax Eclipse XDB-C18 guard column were used for separation. Before the injections, the solutions of the standards and the extracts were filtered through a $0.45 \mu \mathrm{m}$ PTFE syringe filter. Mixture of water, methanol and formic acid in proportions 93:5:2 ( $v: v: v)$ and $3: 95: 2(v: v: v)$ were used as solvents $A$ and $B$, respectively. Separation was performed at $40{ }^{\circ} \mathrm{C}$ using following protocol: $0 \min 20 \%$ B, $10 \min 40 \%$ B, $35 \min 50 \%$ B. The flow rate was $1.0 \mathrm{ml} / \mathrm{min}$. Applied volume was $10 \mu \mathrm{l}$ or 80 $\mu \mathrm{L}$ for non-hydrolyzed or hydrolyzed samples, respectively. The peak assignment and identification was based on comparison of retention times of peaks in sample chromatogram and UV spectra with those of the standards.

\section{Spectrophotometric Determinations of Total Phenols, Flavonoids and Phenolic Acids}

Total phenol content (TP) in the extracts was determined by the Folin-Ciocalteau colorimetric method according to previously published procedure, ${ }^{[18]}$ while the total flavonoid (TF) content was assessed by the method of Kumazawa et al.[19] The total phenolic acids (TPA) were determined as described in Nicolle et al. ${ }^{[20]}$ For all the determinations, the modifications were used as described in Jug et al.[21] The amounts of the analyzed substances in the extracts were expressed as $\mathrm{mg} / \mathrm{ml}$ from calibration curves recorded for the standards and expressed as standard equivalents. Namely, TP, TF and TPA were expressed as gallic acid, quercetin and caffeic acid equivalents, respectively. Measurements were performed 
using Stat Fax 3200 (Awareness Technologies, USA) microplate reader.

\section{Free Radical Scavenging Activity}

Free radical scavenging activity (RSA) was evaluated using DPPH free radical. The assay was performed as described in a previous work. ${ }^{[22]}$ Methanolic solution of DPPH (70 $\mu$ l, 0.2 $\mathrm{mg} / \mathrm{mL}$ ) was added to $130 \mu \mathrm{l}$ of either the methanolic solution of the extract (sample) or methanol (negative control). The mixture was left at room temperature in the dark place. After $30 \mathrm{~min}$ absorbance was read at $545 \mathrm{~nm}$. BHA was used as a positive control. RSA for DPPH free radical was calculated according to the Equation 2.

$$
\operatorname{RSA}=\left(A_{\text {control }}-A_{\text {sample }}\right) / A_{\text {control }} \times 100
$$

Where $A_{\text {control }}$ is the absorbance of the negative control (e.g., blank DPPH solution without test compound) and $A_{\text {sample }}$ is the absorbance of the DPPH solution containing extract. RSA was calculated as the concentration of the extract which scavenges $50 \%$ of DPPH free radicals present in the solution (RSA IC $\mathrm{C}_{50}$ ) and expressed as $\mathrm{mg}$ equivalents of herbal material per $\mathrm{ml}$ of the extract ( $\mathrm{mg} \mathrm{HME} / \mathrm{ml}$ ).

\section{Experimental Design}

Design Expert software version 8.0.6 (Stat-Ease, Minneapolis) was employed for the regression analysis and the optimization of the results. A three-level-three-factor, Box-Behnken design (BBD) was employed to determine the best combination of independent extraction variables for the selected dependent variables (responses). The following design parameters were used (coded values are given in brackets): ethanol concentration $(v / v)\left(X_{1}\right)$ was between $0 \%(-1)$ and $100 \%(+1)$; temperature $\left(X_{2}\right)$ was between $20^{\circ} \mathrm{C}(-1)$ and $60^{\circ} \mathrm{C}(+1)$; $\mathrm{pH}$ of extraction solvent $\left(X_{3}\right)$ was between $5.5(-1)$ and $8.5(+1)$. Extraction yield, TP, TF, TPA and RSA IC 50 were selected as the responses. Measurements were performed in triplicates. Experimental data were fitted to a quadratic polynomial model as described by the following quadratic equation (3):

$$
Y=A_{0}+\sum_{i=1}^{k} A_{i} X_{i}+\sum_{i=1}^{k} A_{i i} X_{i}^{2}+\sum_{i=1}^{k-1} \times \sum_{j=1+1}^{k} A_{i j} X_{i} X_{j}
$$

where $Y$ is the dependent variable; $A_{0}, A_{i}, \mathrm{~A}_{\mathrm{i}}$, and $A_{\mathrm{ij}}$ are the regression coefficients for intercept, linearity, square and interaction, respectively; $X_{\mathrm{i}}$ and $X_{\mathrm{j}}$ are the independent variables.

\section{RESULTS AND DISCUSSION}

\section{Process Parameters}

UAE was utilized to efficiently extract the phenolic compounds from $M$. sativa aerial parts. The experiment
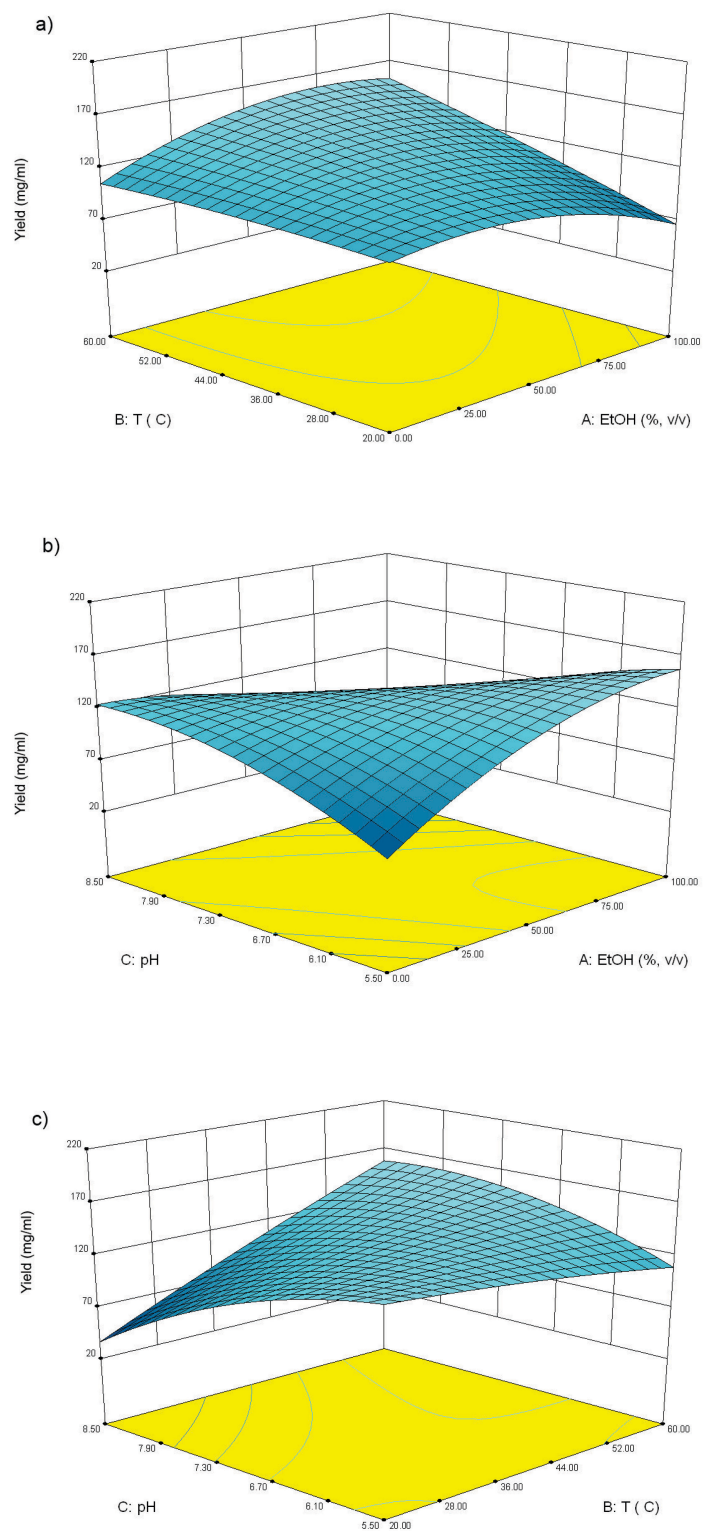

Figure 1. Response surface plots for the yield of Medicago sativa extraction. a) Influence of ethanol content and temperature at $\mathrm{pH}=7$; b) Influence of ethanol content and $\mathrm{pH}$ at $40{ }^{\circ} \mathrm{C}$; c) Influence of temperature and $\mathrm{pH}$ in $50 \%$ ethanol.

was carried out according to a Box-Behnken design based on RSM. It is a three-level spherical and revolving design suitable for fitting second-order response surfaces. Its rationality and excellent outcomes make it appropriate for optimization of chemical and physical processes. [23] Three independent variables selected for optimization were ethanol concentration in water $(\% v / v)$, extraction 
Table 2. Analysis of variance (ANOVA) for the fitted quadratic polynomial model for optimization of extraction parameters

\begin{tabular}{|c|c|c|c|c|c|c|c|c|c|c|}
\hline \multicolumn{6}{|c|}{ Yield $\left(r^{2}=0.9705\right)$} & \multicolumn{5}{|c|}{ Total phenols $\left(r^{2}=0.8517\right)$} \\
\hline Source & SS & df & MS & F Value & $P$-value & SS & $\mathrm{df}$ & MS & FValue & $P$-value \\
\hline Model & 26825.33 & 9 & 2980.5920 & 25.63 & 0.0002 & 3.402 & 9 & 0.3780 & 4.47 & 0.0306 \\
\hline Lack of Fit & 467.00 & 3 & 155.6667 & 1.79 & 0.2878 & 0.389 & 3 & 0.1297 & 2.56 & 0.1933 \\
\hline \multirow[t]{2}{*}{ Pure Error } & 347.20 & 4 & 86.8000 & & & 0.203 & 4 & 0.0508 & & \\
\hline & \multicolumn{5}{|c|}{ Total flavonoids $\left(r^{2}=0.8702\right)$} & \multicolumn{5}{|c|}{ Total phenolic acids $\left(r^{2}=0.8345\right)$} \\
\hline Source & SS & $\mathrm{df}$ & MS & FValue & $P$-value & SS & $\mathrm{df}$ & MS & FValue & $P$-value \\
\hline Model & 0.014 & 9 & 0.0015 & 5.21 & 0.0203 & 0.018 & 9 & 0.0020 & 3.92 & 0.0426 \\
\hline Lack of Fit & 0.001 & 3 & 0.0004 & 2.55 & 0.1939 & 0.003 & 3 & 0.0008 & 3.15 & 0.1481 \\
\hline Pure Error & 0.001 & 4 & 0.0002 & & & 0.001 & 4 & 0.0003 & & \\
\hline \multicolumn{11}{|c|}{ Radical scavenging activity $\left(\mathrm{IC}_{50}\right)\left(r^{2}=0.8265\right)$} \\
\hline Source & SS & $d f$ & MS & F Value & $P$-value & & & & & \\
\hline Model & 67.036 & 9 & 7.4485 & 3.70 & 0.0491 & & & & & \\
\hline Lack of Fit & 3.038 & 3 & 1.0126 & 0.37 & 0.7817 & & & & & \\
\hline Pure Error & 11.035 & 4 & 2.7587 & & & & & & & \\
\hline
\end{tabular}

$\mathrm{SS}=$ Sum of Squares; $\mathrm{df}=$ degrees of freedom; $\mathrm{MS}=$ Mean Square

temperature and $\mathrm{pH}$. Those parameters, according to the results of preliminary experiments, as well as published literature, ${ }^{[10,24]}$ can significantly affect extraction of phenolic compounds from medicinal plants, as well as their activity, including antiradical activity. Since this work was directed at preparation of extracts suitable for preparation of food supplements, only the effects of relatively small $\mathrm{pH}$ changes were investigated. The ethanol concentration and the temperature, on the other hand, were investigated in a relatively wide range of conditions.

The selected responses were extraction yield and radical scavenging activity, as well as the content of phenolic antioxidants (total phenol, total flavonoid and total phenolic acids). Table 1 shows the process variables and experimental data of 17 runs. By applying multiple regression analysis on the experimental data and by analysis of variance (ANOVA) for the selected models (Table 2 ) it was found that the relationship between the response variables and independent variables can best be expressed by the quadratic polynomial equations. The F-value of all the models was higher than 3.70, while the $P$-values were lower than 0.05. This indicates that the models are significant and that they can be used to optimize the extraction variables. The value of lack of fit test in all the models was statistically insignificant relative to the pure error and indicates that the fitting model is adequate to describe the experimental data. The determination coefficients for all the responses were relatively high $\left(0.8265 \leq r^{2} \leq 0.9705\right)$ showing reasonably good predictability of the results by the selected models. The simplest and the most intuitive way to observe the effects of any independent variable on the selected response is to generate response surface plots of the model. This can be done by plotting the response values against two variables in the investigated experimental range, while holding the third variable at a fixed level. Figures 1-3 show the surface plots which are presenting the influence of investigated UAE parameters on the yield, TP, TF, TPA and RSA IC $C_{50}$. The plots were produced for each pair of dependent variables, whereas the third variable was taken as a constant at its middle level. Presented plots enable simple visualization of the influence and interaction between the parameters in the design. In addition, the results are presented as polynomial equations which provide the most accurate description of the relationships between dependent and independent variables.

\section{Yield of the Extraction}

Yield of the extraction was calculated as the weight of dry matter in $1 \mathrm{ml}$ of the extract. Final equation in terms of coded factors is as follows (significant model terms are marked with an asterisk):

$$
\begin{aligned}
& \text { Yield }(\mathrm{mg} / \mathrm{g})=133.60+2.00 \times X_{1}+21.75 \times X_{2}\left({ }^{*}\right) \\
& -14.75 \times X_{3}\left({ }^{*}\right)+21.50 \times X_{1} \times X_{2}\left({ }^{*}\right) \\
& -48.50 \times X_{1} \times X_{3}\left({ }^{*}\right)+39.00 \times X_{2} \times X_{3}\left({ }^{*}\right) \\
& -22.80 \times X_{1}^{2}-3.30 \times X_{2}^{2}\left({ }^{*}\right)-18.30 \times X_{3}^{2}\left({ }^{*}\right)
\end{aligned}
$$

The results have shown that the yield was significantly influenced by the $\mathrm{pH}$ and temperature of the extraction solvent as linear variables, as well as by the ethanol content and $\mathrm{pH}$ as quadratic terms. In addition to that, the yield was influenced by the interactions of all the three extraction variables.

As it can be observed in Figure 1, combination of low ethanol content with low $\mathrm{pH}$, as well as high ethanol content with high $\mathrm{pH}$, acted detrimentally on the yield 
a)

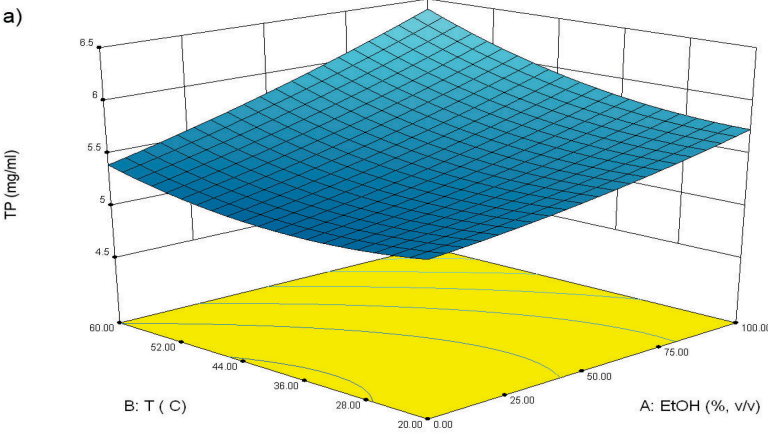

b)

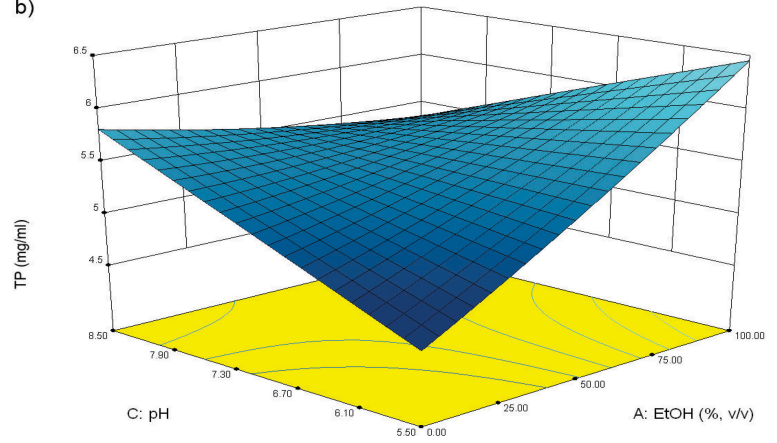

c)

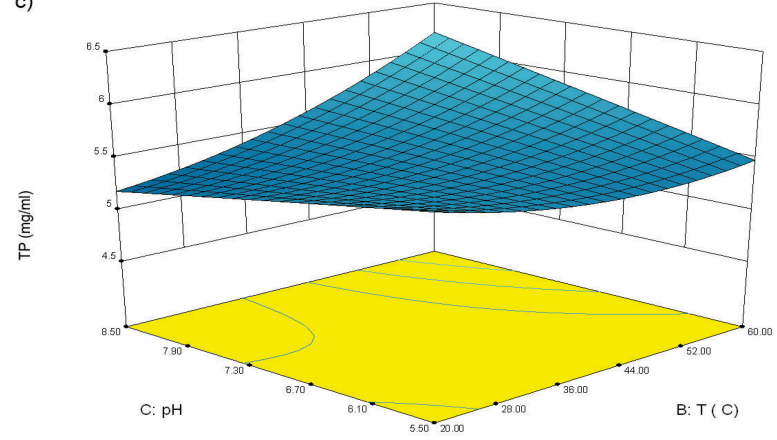

d)

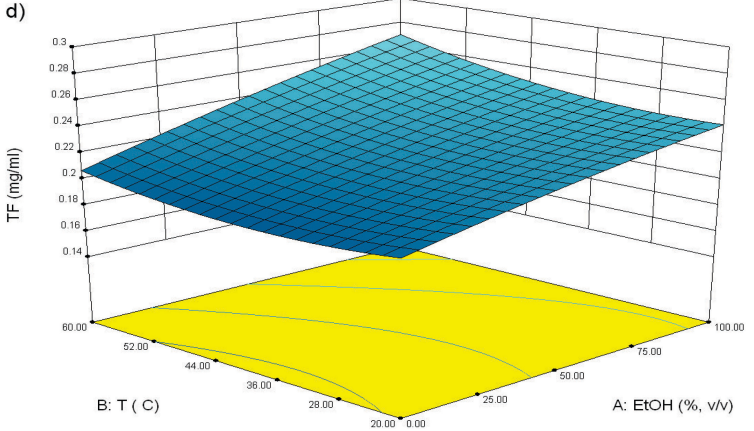

e)

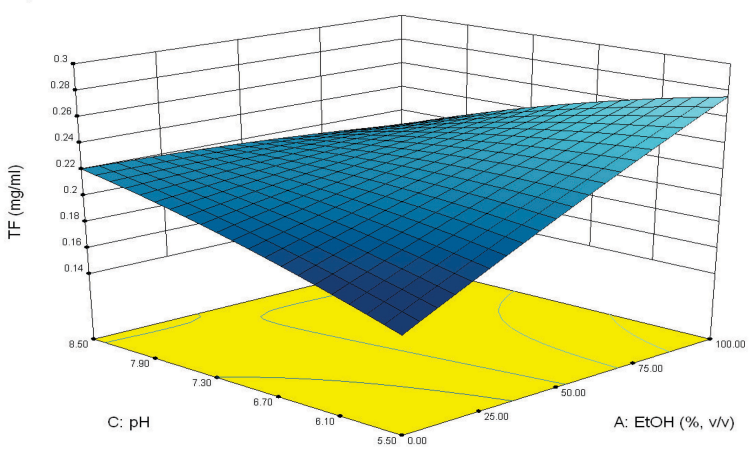

f)

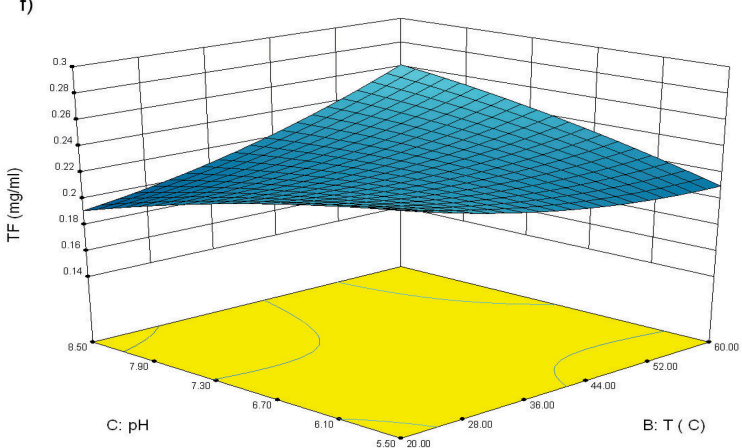

Figure 2. Response surface plots for total phenol (TP) content (a-c) and total flavonoid (TF) content (d-f) in Medicago sativa extracts. a,d) Influence of ethanol content and temperature at $\mathrm{pH}=7 ; \mathrm{b}, \mathrm{e}$ ) Influence of ethanol content and $\mathrm{pH}$ at $\left.40{ }^{\circ} \mathrm{C} ; \mathrm{c}, \mathrm{f}\right)$ Influence of temperature and $\mathrm{pH}$ in $50 \%$ ethanol.

(Figure 1b). At higher $\mathrm{pH}$, the yield was mostly influenced by the changes in temperature, where higher temperature lead to better extraction, while at low $\mathrm{pH}$, changes in temperature did not cause major changes of yield (Figure 1c). The complex relationship between yield and the independent variables, as well as a large number of significant terms, reflects a variety of influences of the examined extraction conditions on numerous phytochemicals present in the $M$. sativa extracts, as discussed further.

\section{Total Phenols, Flavonoids and Phenolic Acids}

Phenols from $M$. sativa can also act as strong antioxidant agents and contribute to the observed biological effects. For example, several well know bioactive flavonoids, such as kaempferol, hyperoside, quercetin and luteolin, were also identified in $M$. sativa aerial parts. ${ }^{[3,25]}$ In addition, phenolic acids have also been found in $M$. sativa extracts. Examples include hydroxyl benzoic acids, ferulic acid, 
a)

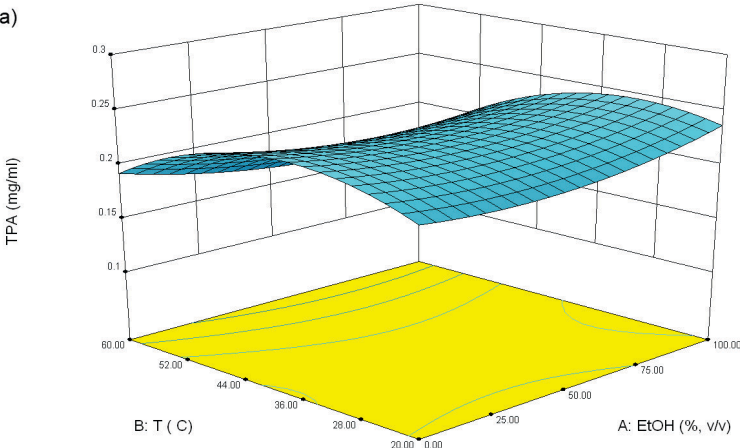

b)

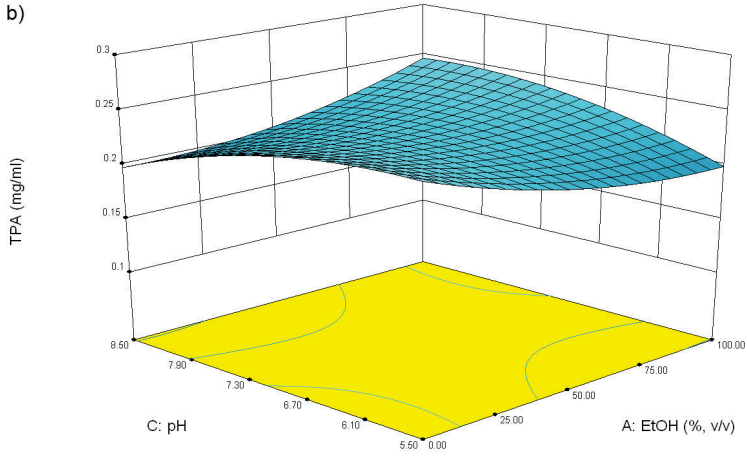

c)

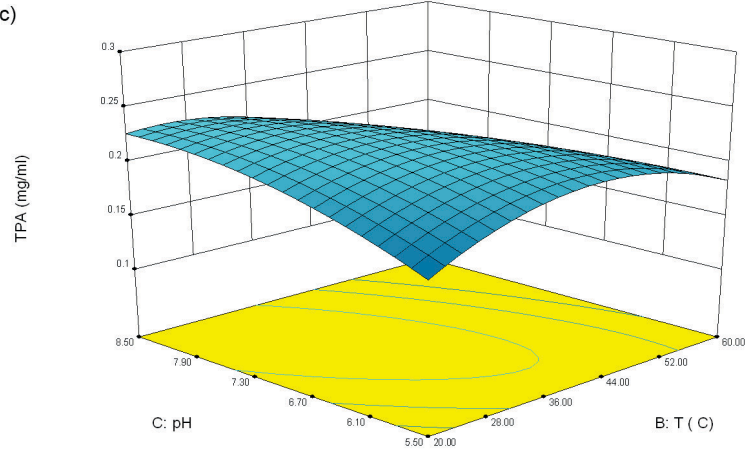

d)
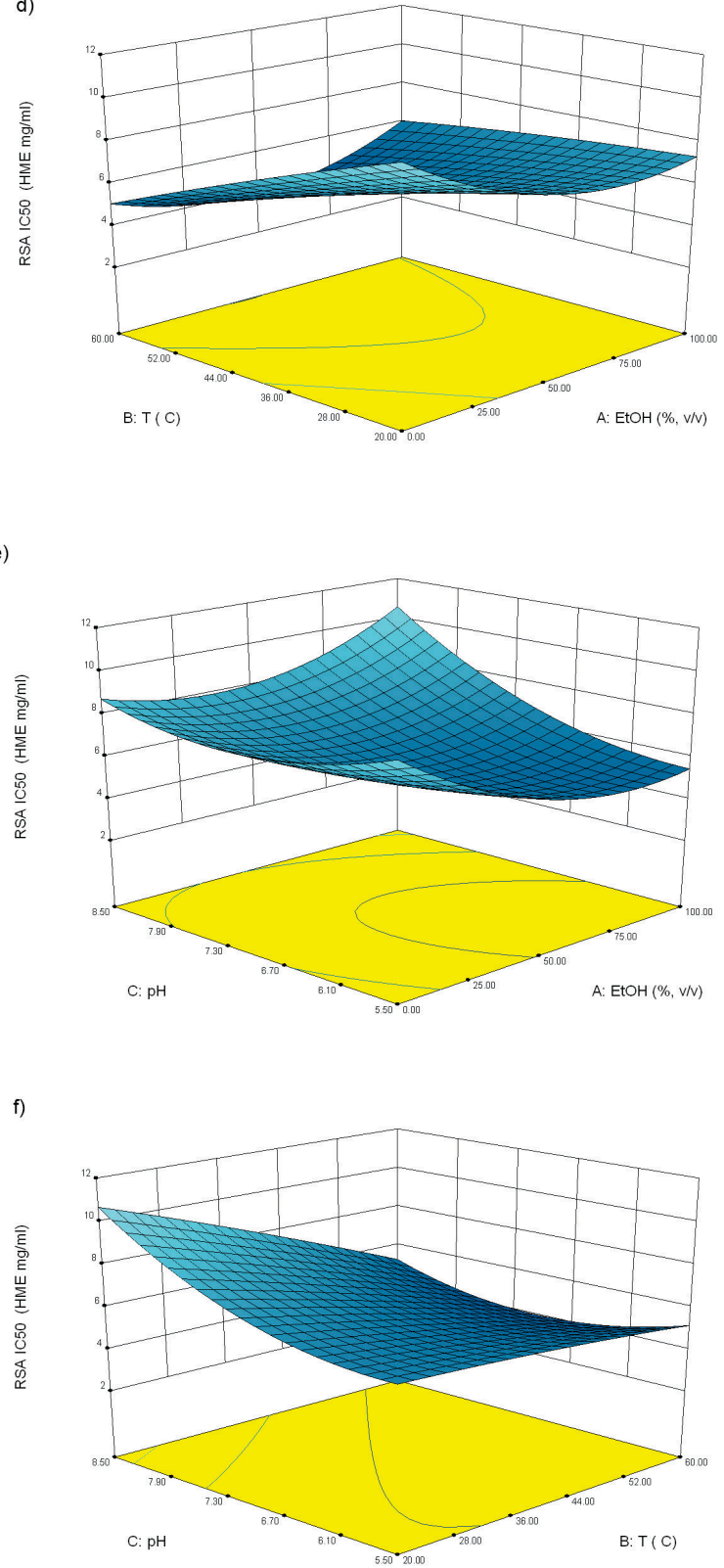

Figure 3. Response surface plots for total phenolic acid (TPA) content (a-c) and radical scavenging activity (RSA IC $\left.\mathrm{C}_{50}\right)(\mathrm{d}-\mathrm{f})$ of Medicago sativa extracts. a,d) Influence of ethanol content and temperature at $\mathrm{pH}=7 ; \mathrm{b}, \mathrm{e}$ ) Influence of ethanol content and $\mathrm{pH}$ at $\left.40{ }^{\circ} \mathrm{C} ; \mathrm{C}, \mathrm{f}\right)$ Influence of temperature and $\mathrm{pH}$ in $50 \%$ ethanol.

caffeic acid and $\beta$-phenyl caffeate. Among other phenolics there were silbens (pterostilbene), pterocarpans (medicarpin), coumestans (coumestrol), as well as coumarins (myrsellinol, scopoletin, esculetin).[2,3,25,26] These and other dietary polyphenols, as well as their metabolites, may reduce the risk of the development of type 2 diabetes complications, cardiovascular diseases or even cancer. ${ }^{[27]}$ For example, it was found that several phenolic compounds in M. sativa extract (medicarpin, melilotocarpan, millepurpan, tricin, and chrysoeriol) contribute to the cytotoxicity and apoptosis induced in sensitive and multidrug-resistant tumor cells. ${ }^{[8]}$ Therefore, 
the content of phenols (TP, TF and TPA) was also assessed and presented in Table 1. Polynomial equations for TP, TF and TPA in terms of coded factors are presented below (significant model terms are marked with an asterisk):

$$
\begin{aligned}
& \operatorname{TP}(\mathrm{mg} / \mathrm{ml})=5.488+0.369 \times X_{1}\left({ }^{*}\right)+200 \times X_{2} \\
& +0.051 \times X_{3}+0.129 \times X_{1} \times X_{2}-0.594 \times X_{1} \times X_{3}\left({ }^{*}\right)+ \\
& 0.306 \times X_{2} \times X_{3}+0.055 \times X_{1}^{2}+0.158 \times X_{2}^{2}-0.003 \times X_{3}^{2} \\
& \operatorname{TF}(\mathrm{mg} / \mathrm{ml})=0.224+0.026 \times X_{1}\left({ }^{*}\right)+0.009 \times X_{2} \\
& -0.001 \times X_{3}+0.005 \times X_{1} \times X_{2}-0.032 \times X_{1} \times X_{3}\left({ }^{*}\right) \\
& +0.027 \times X_{2} \times X_{3}\left({ }^{*}\right)-0.002 \times X_{1}^{2}+0.009 \times X_{2}^{2} \\
& -0.005 \times X_{3}^{2} \\
& \operatorname{TPA}\left(\mathrm{mg} / \mathrm{ml}^{2}\right)=0.226-0.001 \times X_{1}-0.023 \times X_{2}\left({ }^{*}\right) \\
& -0.001 \times X_{3}-0.011 \times X_{1} \times X_{2}+0.025 \times X_{1} \times X_{3} \\
& -0.03 \times X_{2} \times X_{3}\left({ }^{*}\right)+0.013 X_{1}^{2}-0.036 \times X_{2}^{2}\left({ }^{*}\right) \\
& -0.015 \times X_{3}^{2}
\end{aligned}
$$

The extracts contained between $4.70 \mathrm{mg} / \mathrm{ml}$ and 6.62 $\mathrm{mg} / \mathrm{ml}$ of TP, while the content of TF in the extracts varied between $0.175 \mathrm{mg} / \mathrm{ml}$ and $0.283 \mathrm{mg} / \mathrm{ml}$. Both responses were positively influenced by the amount of ethanol in the extraction medium as linear term, as well as negatively influenced by interaction of the ethanol content and $\mathrm{pH}$.

This could also be observed in Figure 2 where high ethanol content leads to an increase of TP and TF content at medium (Figure $2 \mathrm{a}$ and $2 \mathrm{~d}$ ) and low $\mathrm{pH}$ (Figure $2 \mathrm{~b}$ and 2e). At high $\mathrm{pH}$, lower ethanol content is somewhat better suited for extraction of both TP and TF (Figure $2 b$ and $2 e$ ). The positive influence of polar organic solvent, such as ethanol and methanol, on TP and TF, as well as favorable influence of low $\mathrm{pH}^{[10]}$ has previously been observed in extraction of several plant species including Artemisia absinthium, Allium ursinum and Myrcaria species. ${ }^{[28]}$ The amount of TPA in the prepared extracts was between 0.120 $\mathrm{mg} / \mathrm{ml}$ and $0.271 \mathrm{mg} / \mathrm{ml}$. Their content depended mostly on temperature of the extraction solvent, both as linear and quadratic term, as well as on its interaction with $\mathrm{pH}$. Mild temperatures at higher $\mathrm{pH}$ (Figure $3 \mathrm{c}$ ) were the most appropriate for phenolic acids extraction. Dual effect that $\mathrm{pH}$ has on the extraction of phenols investigated in scope of this work (TP, TF and TPA) may be explained by their chemical properties. Phenols have significantly lower pKa values than aliphatic alcohols. The presence of orthoand/or para- hydroxyl groups in many natural polyphenols additionally lowers their pKa values which makes them even better proton donors and improves their solubility in water. This is probably the rationale behind the beneficial effects that higher $\mathrm{pH}$ exerts on the observed extractability of TPA. However, besides increasing ionization and aqueous solubility, basic media may cause reversible or, at high $\mathrm{pH}$ and/or presence of metal ions, irreversible changes of their chemical structure. Some polyphenolic molecules are especially susceptible to $\mathrm{pH}$ changes. For example, it is known that flavonols with catechol B-ring can autoxidize in the presence of oxygen to produce semiquinone-and quinone-type metabolites. ${ }^{[11,29]}$ According to previous research, $M$. sativa aerial parts are rich in quercetin and luteolin, flavonoids who share such structural feature. ${ }^{[30]}$ This may partly explain the observed negative effect of higher $\mathrm{pH}$ on extraction of TF and TP.

Although the detailded analysis of the influence of extraction of extraction conditions is outside the scope of this work, HPLC analysis was performed in order to detect the major phenolic compounds of the prepared extracts. In accordance with some previous works, ${ }^{[31]}$ the results have shown that the main phenolic compound in the extracts was ferulic acid which constituted approximately 5-15\% of the prepared extracts. In addition to that, chromatograms of the extracts subjected to hydroliysis (Figure 4) shows that the glycosides of apigenin and kaempferol were present, as well as a small amount of $p$-coumaric acid.

\section{Radical Scavenging Activity of the Extracts}

Radical scavenging activity of the extracts was investigated using DPPH free radicals. The reactivity of antioxidants with DPPH free radicals is based on single electron transfer. ${ }^{[32]}$ This leads to a decrease in the absorbance of the DPPH radicals as determined spectrophotometrically at $517 \mathrm{~nm}$. It is a relatively simple method suitable for determination of antiradical activity of a large number of natural extracts in relatively short time, which makes this model one of the most commonly used in literature. ${ }^{[12,13,24]}$ In the presented work, RSA IC 50 values of $M$. sativa extracts ranged between 3.27 and $11.15 \mathrm{mg} / \mathrm{g}$. BHA, used as a positive control in this assay, presented RSA IC 50 of $0.043 \pm 0.004 \mathrm{mg} / \mathrm{ml}$.

The relationship between $\mathrm{RSA} I \mathrm{IC}_{50}$ and coded independent variables is presented in the equation below (significant model terms are marked with an asterisk):

$$
\begin{aligned}
& \mathrm{RSAIC}_{50}(\mathrm{mg} / \mathrm{ml})=57.409-4.874 \times X_{1} \\
& -16.049 \times X_{2}\left(^{*}\right)+11.517 \times X_{3}+9.817 \times X_{1} \times X_{2} \\
& +14.042 \times X_{1} \times X_{3}-11.016 \times X_{2} \times X_{3}+15.632 \times X_{1}^{2} \\
& -1.236 \times X_{2}^{2}+12.081 \times X_{3}^{2}
\end{aligned}
$$

Radical scavenging activity of the extracts was significantly influenced by the temperature at which the extraction was performed. Higher temperatures were better suited for the extraction of compounds with radical scavenging properties (Figure $3 \mathrm{~d}$ and $3 \mathrm{e}$ ). It was shown that $M$. sativa flowers also display notable DPPH radical scavenging activity. ${ }^{[33]}$ Flavonoids are predominantly located in aerial 


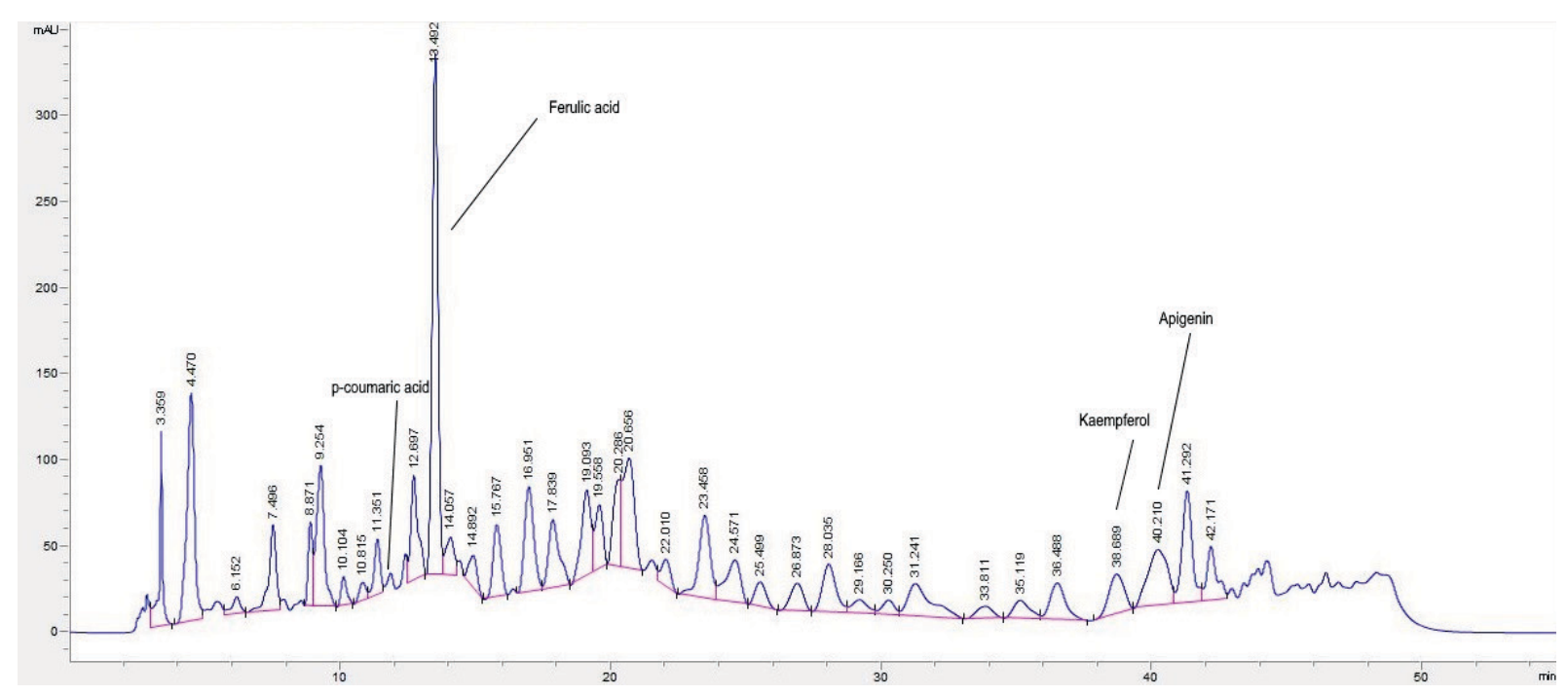

Figure 4. Chromatogram of Run 5 extract after acid hydrolysis (detection at $320 \mathrm{~nm}$ ).

parts of the plants because synthesis of quercetin and other flavonoid derivatives is induced by the sunlight. ${ }^{[3]}$ The role of flavonoids as radical scavengers ${ }^{[34]}$ in the extracts of $M$. sativa aerial parts is confirmed in this work by the observed negative correlation $(P<0.05)$ between TF and RSA IC 50 . However, coefficient of determination was relatively low $\left(r^{2}\right.$ $=0.2944)$. In addition, RSA did not correlate with the other investigated responses. This lack of correlation indicates that some of the compounds whose content was not determined in the course of this work are also involved in antiradical activity of the investigated extracts. This is corroborated by the observation that phenols make only a small portion of dry matter (yield) of the extracts (Table 1), as well as by the negative correlation between RSA I $C_{50}$ and the yield of the extraction with higher coefficient of determination $\left(r^{2}=0.5417\right)$ than the one observed with TF. $M$. sativa is a source of polysaccharides with the immunomodulating properties ${ }^{[3]}$ and peptides with antioxidant properties. ${ }^{[4]}$ Knowing that natural polysaccharides and proteins may react with DPPH free radical, $[4,35]$ we may conclude that at least some of the observed antiradical activity of $M$. sativa extracts could be attributed to the content of those macromolecules.

\section{Optimization of the Extraction Process}

The aim of this study was to maximize the total extraction yield, the yield of the target compounds (total phenols, flavonoids and phenolic acids) as well as DPPH radical scavenging activity of the $M$. sativa extracts, within studied extraction parameters range. Based on the experimental results and statistical analysis, numerical optimizations have been conducted in order to establish the optimum levels of independent variables. Determination of optimal extraction conditions, and the predicted values of corresponding responses, was based on desirability function (D), which was higher than 0.9 for all the analyzed responses. In the current study, each of the selected responses was best optimized under different extraction conditions (Table 3).

Low concentration of ethanol, applied at high temperatures and low $\mathrm{pH}$, resulted in a good extraction yield. Phenolic analytes were best extracted using $100 \%$ ethanol. TP and TF were best extracted at pH 5.5 while TPA needed more basic $\mathrm{pH}$ (8.5). While TF and TPA were sensitive to elevated temperatures, TP was best extracted at $60^{\circ} \mathrm{C}$. The selected conditions were applied for preparation of extracts with the desired properties. The predicted results matched well with the experimental ones, with low RSDs, indicating good suitability of the selected models (Table 3 ).

\section{CONCLUSIONS}

In the present study, RSM using Box-Behnken design was successfully employed to optimize the extraction conditions for functional components of Medicago sativa aerial parts. The optimum extraction conditions (ethanol concentration, extraction temperature and $\mathrm{pH}$ ) were determined for achievement of maximum total extraction yield and DPPH radical scavenging activity, as well as the yield of several classes of phenolic compounds such as total phenols, total flavonoids and total phenolic acids. The results have shown that the most important variable for achievement of high total phenol and flavonoid content 
Table 3. Estimated, predicted and observed values for the response variables

\begin{tabular}{|c|c|c|c|c|c|c|c|}
\hline Optimized response & Aim of the optimization & $\mathrm{X}_{1} / \%$ & $\mathrm{X}_{2} /{ }^{\circ} \mathrm{C}$ & $x_{3}$ & Predicted & Observed & RSD (\%) \\
\hline Yield (mg/ml) & maximized & 20 & 60 & 5.5 & 162 & 172 & 5.81 \\
\hline TP $(\mathrm{mg} / \mathrm{ml})$ & maximized & 100 & 60 & 5.5 & 6.63 & 7.02 & 5.56 \\
\hline $\mathrm{TF}(\mathrm{mg} / \mathrm{ml})$ & maximized & 100 & 23 & 5.5 & 0.292 & 0.311 & 6.11 \\
\hline TPA (mg/ml) & maximized & 100 & 23 & 8.5 & 0.275 & 0.265 & -3.77 \\
\hline $\mathrm{RSA} \mathrm{IC}_{50}(\mathrm{mg} \mathrm{HME} / \mathrm{ml})$ & minimized & 40 & 60 & 7.0 & 3.97 & 3.73 & -6.43 \\
\hline
\end{tabular}

$\mathrm{X}_{1}$ - Ethanol concentration; $\mathrm{X}_{2}-$ Temperature $\mathrm{X}_{3}-\mathrm{pH}$ of extraction solvent.

was ethanol concentration, while the temperature was the most important variable for extraction of phenolic acids and antiradical activity of the extracts. The diversity of optimum conditions obtained by RSM indicates that the extraction settings should be carefully selected according to the desired results.

Acknowledgment. We kindly thank Vedran Šegota, expert associate at the Department of Botany, Faculty of science, University of Zagreb for identification of plant material. Financial support of University of Zagreb in the frame of the project Isolation and modulation of antioxidative properties of plant polyphenols by the use of cyclodextrins is kindly acknowledged. The funding source had no involvement in the content of the presented paper.

\section{REFERENCES}

[1] E. Basch, C. Ulbricht, M. Harrison, D. Sollars, M. Smith, C. Dennehy, P. Szapary, J. Herb. Pharmacother. 2003, 3, 69 .

[2] K. S. Bora, A. Sharma, Pharm. Biol. 2011, 49, 211.

[3] A. Gholami, N. De Geyter, J. Pollier, S. Goormachtig, A. Goossens, Nat. Prod. Rep. 2014, 31, 356.

[4] Z. Xie, J. Huang, X. Xu, Z. Jin, Food Chem. 2008, 111, 370.

[5] C. Manach, A. Scalbert, C. Morand, C. Rémésy, L. Jiménez, Am. J. Clin. Nutr. 2004, 79, 727.

[6] A. H. Olah, R. T. Sherwood, Phytopathology 1973, 63, 739.

[7] S. M. Boué, T. E. Wiese, S. Nehls, M. E. Burow, S. Elliott, C. H. Carter-Wientjes, B. Y. Shih, J. A. McLachlan, T. E. Cleveland, J. Agric. Food Chem. 2003, 51, 2193.

[8] G. Gatouillat, A. A. Magid, E. Bertin, M.-G. OkiemyAkeli, H. Morjani, C. Lavaud, C. Madoulet, Nutr. Cancer 2014, 66, 483.

[9] S. R. Shirsath, S. Sonawane, P. Gogate, Chem. Eng. Process. Process Intensif. 2012, 53, 10.

[10] S. Rodrigues, F. Fernandes, E. Brito, A. Sousa, N. Narain, Ind. Crops Prod. 2015, 69, 400.

[11] Z. Jurasekova, A. Torreggiani, M. Tamba, S. SanchezCortes, J. V. Garcia-Ramos, J. Mol. Struct. 2009, 918, 129.
[12] P. Izadiyan, B. Hemmateenejad, Food Chem. 2016, 190, 864.

[13] F. Dahmoune, B. Nayak, K. Moussi, H. Remini, K. Madani, Food Chem. 2015, 166, 585.

[14] Y. Liu, S. Wei, M. Liao, Ind. Crops Prod. 2013, 49, 837.

[15] J. Wu, D. Yu, H. Sun, Y. Zhang, W. Zhang, F. Meng, X. Du, Ind. Crops Prod. 2015, 69, 68.

[16] A. Krakowska, K. Rafińska, J. Walczak, T. Kowalkowski, B. Buszewski, J. AOAC Int. 2017, DOI 10.5740/jaoacint.17-0234.

[17] C.-L. Jing, X.-F. Dong, J.-M. Tong, Mol. Basel Switz. 2015, 20, 15550.

[18] V. L. Singleton, R. Orthofer, R. M. Lamuela-Raventós, in Methods Enzymol., Academic Press, 1999, pp. 152-178.

[19] S. Kumazawa, T. Hamasaka, T. Nakayama, Food Chem. 2004, 84, 329.

[20] C. Nicolle, A. Carnat, D. Fraisse, J.-L. Lamaison, E. Rock, H. Michel, P. Amouroux, C. Rémésy, J. Sci. Food Agric. 2004, 84, 2061.

[21] M. Jug, M. Z. Končić, I. Kosalec, LWT - Food Sci. Technol. 2014, 57, 530.

[22] M. Z. Končić, M. Barbarić, I. Perković, B. Zorc, Mol. Basel Switz. 2011, 16, 6232.

[23] C.-H. Dong, X.-Q. Xie, X.-L. Wang, Y. Zhan, Y.-J. Yao, Food Bioprod. Process. 2009, 87, 139.

[24] N. Xynos, G. Papaefstathiou, E. Gikas, A. Argyropoulou, N. Aligiannis, A.-L. Skaltsounis, Sep. Purif. Technol. 2014, 122, 323.

[25] M. A. Hanif, A. Y. Al-Maskari, J. N. Al-Sabahi, I. AlHdhrami, M. M. Khan, A. Al-Azkawi, A. I. Hussain, Nat. Prod. Res. 2015, 29, 2332.

[26] L. M. Martin, M. C. Castilho, M. I. Silveira, J. M. Abreu, J. Liq. Chromatogr. Relat. Technol. 2006, 29, 2875.

[27] D. Del Rio, A. Rodriguez-Mateos, J. P. E. Spencer, M. Tognolini, G. Borges, A. Crozier, Antioxid. Redox Signal. 2013, 18, 1818.

[28] S. Sahin, O. Aybastıer, E. Işık, Food Chem. 2013, 141, 1361.

[29] Z. Jurasekova, C. Domingo, J. V. Garcia-Ramos, S. Sanchez-Cortes, Phys. Chem. Chem. Phys. PCCP 2014, 16, 12802. 
[30] P. Seguin, W. Zheng, A. Souleimanov, J. Agron. Crop Sci. 2004, 190, 211.

[31] K. Rafińska, P. Pomastowski, O. Wrona, R. Górecki, B. Buszewski, Phytochem. Lett. 2017, 20, 520.

[32] A. Căta, M. Ştefănuţ, R. Pop, C. Tănasie, C. Moşoarcă, A. D. Zamfir, Croat. Chem. Acta 2016, 89, 37.
[33] A. Caunii, G. Pribac, I. Grozea, D. Gaitin, I. Samfira, Chem. Cent. J. 2012, 6, 123.

[34] D. Amić, D. Davidović-Amić, D. Bešlo, N. Trinajstić, Croat. Chem. Acta 2003, 76, 55.

[35] D. Hua, D. Zhang, B. Huang, P. Yi, C. Yan, Carbohydr. Polym. 2014, 103, 143. 